\title{
Self-assembly of nanostructures obtained in a microwave-assisted oxidative polymerization of aniline
}

\author{
M. R. Gizdavic-Nikolaidis ${ }^{1,2}$, M. M. Jevremovic ${ }^{3}$, M. C. Allison ${ }^{1}$, D. R. Stanisavljev ${ }^{2}$, \\ G. A. Bowmaker ${ }^{1}$, Z. D. Zujovic ${ }^{1,4,5^{*}}$ \\ ${ }^{1}$ School of Chemical Sciences, The University of Auckland, Private Bag 92019, 1142 Auckland, New Zealand \\ ${ }^{2}$ Faculty of Physical Chemistry, Studentski Trg 12-16, 11001 Belgrade, Serbia \\ ${ }^{3}$ Nuclear Facilities of Serbia, 12-14 Mike Petrovica Alasa, Vinca, 11351 Belgrade, Serbia \\ ${ }^{4}$ Institute of General and Physical Chemistry, Studentski Trg 12-16, 11001 Belgrade, Serbia \\ ${ }^{5}$ MacDiarmid Institute for Advanced Materials and Nanotechnology, Victoria University of Wellington, 6140 Wellington, \\ New Zealand
}

Received 9 April 2014; accepted in revised form 26 May 2014

\begin{abstract}
For the first time, microwave assisted aniline oxidative polymerization is performed in the presence of acetic acid $\left(\mathrm{CH}_{3} \mathrm{COOH}\right)$ and ammonium hydroxide $\left(\mathrm{NH}_{4} \mathrm{OH}\right)$ at different microwave power levels. The reaction system is kept at constant temperature of $24 \pm 1{ }^{\circ} \mathrm{C}$. The products are investigated by Fourier Transform Infrared Spectroscopy (FTIR), Raman, solid-state Nuclear Magnetic Resonance (NMR) and Electron Paramagnetic Resonance (EPR) spectroscopies. EPR signals in polyaniline (PANI) originate from the polarons formed upon protonation and doping by acid. The microwave radiation causes an increase in the spin concentration which is slightly more evident for $8 \mathrm{~W}$ than for $93 \mathrm{~W}$. The morphology is investigated by using scanning electron microscopy (SEM). SEM micrographs revealed the formation of nanorods (in the presence of $\mathrm{CH}_{3} \mathrm{COOH}$ ) and nanospheres (in the presence of $\mathrm{NH}_{4} \mathrm{OH}$ ). FTIR, Raman and solid-state NMR spectroscopies indicate the presence of PANI and aniline oligomers. X-ray Diffraction (XRD) measurements showed the presence of well-ordered structures.
\end{abstract}

Keywords: polymer synthesis, molecular engineering, microwave-enhanced, self-assembly, polyaniline, nanomaterials

\section{Introduction}

Polyaniline (PANI) has been one of the most studied electrically conducting polymers. This is mainly because of its simple doping-dedoping REDOX chemistry, ease of synthesis, relatively inexpensive production and ability to yield nanostructured materials of different morphologies. There are different means for obtaining PANI including a chemical, an electrochemical and recently introduced a microwave (MW) assisted methodology [1-3].

Over the last decade the chemical approach i.e. the oxidative polymerization of aniline has been used for the synthesis of wide variety of products with different morphologies and physical and chemical properties [4-14]. The specific characteristics make PANIs applicable in various fields such as gas sensors, biosensors, actuators, anticorrosive coatings, electronic devices etc. [1, 2]. Some of syntheses have been performed at medium or high $\mathrm{pH}(\mathrm{pH}>4)$ compared to standard, relatively low $\mathrm{pH}$ conditions $(\mathrm{pH}<$ 2.5) $[15,16]$. The standard low $\mathrm{pH}$ synthesis in an acidic medium using $1 \mathrm{M} \mathrm{HCl}$ for instance yields morphologically featureless and highly conductive PANIs. On the other hand it has been shown that higher $\mathrm{pH}$ values very often favour self-assembly of well-defined, but less conductive supramolecular

\footnotetext{
${ }^{*}$ Corresponding author, e-mail: z.zujovic@auckland.ac.nz (C) BME-PT
} 
structures: nanotubes, nanospheres, nanorods, nanodisks etc. [17-21]. These can be used directly as formed or indirectly as templates for other PANI based materials which exhibit better conductivity and an improved environmental stability [17]. Therefore, the ever growing need for various applications demands further developments in the field of selfassembly of nanomaterials obtained in the oxidative polymerization of aniline.

A novel method of synthesis of PANI using a microwave assisted approach under controlled temperature (Enhanced Microwave Synthesis - EMS) [22$26]$ has been recently introduced [3, 27]. The reaction vessel is externally cooled while simultaneously irradiated with microwaves. Temperature in the system was measured by a fiber optic temperature sensor preventing interaction with MWs and influence on the temperature reading. This is significantly different from the conventional microwave synthesis (CMS) $[28,29]$ which mainly relies on thermal heating and where the system due to the efficient heating quickly reaches a high temperature. When the reaction system attains the predetermined bulk temperature, the microwave irradiation is turned off ensuring that reagents and products are not degraded by excessive heating. This approach cannot preserve constant temperature of the samples during extended time intervals. In the EMS synthesis a source of microwave heating is finely balanced with external cooling system so that samples may be permanently irradiated keeping the reaction solution at certain bulk temperature. This enables a continuous flow of MW energy into the system which maintains a desired temperature [22, 30-32].

However, the development of materials with specific physicochemical and morphological characteristics tailored to certain applications is constrained by the absence of a theoretical framework relating product characteristics to MW operation. The question whether all effects can be attributed to thermal or to specific thermal and non-thermal effects related to microwave radiation should be answered and taken into account during EMS synthesis. This has sparked a sharp debate that divides the scientific community $[33,34]$. The non-thermal effects are a result of the direct interactions of molecules with electromagnetic irradiation which could change kinetic parameters of the reactions. The specific thermal effects include superheating phenomena, different distribution of heat compared with classical heating and different heating of phases present in the same system producing 'hot spots'. In order to explain the formation mechanism of nanostructured PANIs in MW, we hypothesized that two reaction stages existed, both affected by microwave irradiation: (a) nucleation and (b) chain growth (polymerization) [35]. The first stage is based on instantaneous local heating that develops conditions for homogeneous nucleation. Other effects such as diffusion or molecular agitation could drive the second stage that is also fast. However, the lack of a full understanding as to what mechanisms drive MW effects and the formation of specific PANIs make further studies based on our preliminary data necessary.

Using the EMS approach is important as PANI exhibits better physicochemical characteristics when synthesized at lower temperatures [36, 37]. Besides this, PANI materials have been synthesised on a large scale using the EMS scheme [3, 27]. Also, it has been shown that the EMS yields specific nanostructured materials which open possibilities for upscaled production of polymeric conducting nanostructures $[3,35]$. At the same time, various parameters such as a MW power, reaction time, concentrations of reagents, $\mathrm{pH}$ etc. can be used to tune various chemical and physical properties of PANI such as molecular weight, morphology, conductivity etc. [35].

We have previously reported studies of the selfassembly of various nanostructures synthesized at relatively low temperatures and at initial medium $\mathrm{pH}$ based on a conventional aniline oxidative polymerization approach [18-21, 38-41]. However, using microwave synthesis at low pH PANI was produced in 5 minutes with $80 \%$ yield (synthesized sixty times faster compared to the classical chemical synthesis). Typically, self-assembly favours low temperatures, low concentrations of reactants and long reaction times. The question is whether we can use the EMS for self-assembly knowing that MW accelerates reactions.

Therefore, the idea here is to use the advantages of constant microwave irradiation during the selfassembly process while keeping the reaction temperature low. Is it possible to get nanostructures at initially high and medium $\mathrm{pH}$ using the microwave method, which usually promotes fast syntheses? Will microwaves affect the final products? To gain insight into these matters, a microwave-enhanced 
aniline oxidative polymerization at initial medium and high $\mathrm{pH}$ was carried out.

\section{Experimental methods}

\subsection{Synthesis}

PANI was prepared by aniline oxidation with ammonium persulfate (APS). APS (1.3704 g) was added to an aqueous solution of $0.4 \mathrm{M}$ acetic acid $\left(\mathrm{CH}_{3} \mathrm{COOH}\right)$ or $0.2 \mathrm{M}$ ammonium hydroxide, $\mathrm{NH}_{4} \mathrm{OH}(12 \mathrm{~mL})$, followed by addition of $0.4369 \mathrm{~mL}$ of aniline. The initial $\mathrm{pH}$ values were around 5 and 10 for the $\mathrm{CH}_{3} \mathrm{COOH}$ and $\mathrm{NH}_{4} \mathrm{OH}$ mediums, respectively. Information on chemicals: 1) Aniline, ACS reagent, $\geq 99.5 \%$, Sigma Aldrich, CAS Number 62-53-3;2) Ammonium persulphate, reagent grade 98\%, Sigma Aldrich, CAS Number 7727-54-0;3) Ammonium hydroxide, ACS reagent, $28.0-30.0 \% \mathrm{NH}_{3}$ basis, Sigma Aldrich, CAS Number 1336-21-6; 4) Acetic acid, Acetic acid - Glacial acetic acid, 99.7+\%, ACS reagent, Acros Organic, CAS Number 64-19-7. The MW PANI synthesis using $\mathrm{CH}_{3} \mathrm{COOH}$ and $\mathrm{NH}_{4} \mathrm{OH}$ was performed at three power levels, 0,8 and $93 \mathrm{~W}$ for 10 and $20 \mathrm{~min}$. The synthesis performed at $0 \mathrm{~W}$ is equivalent to a classical chemical synthesis (CS). The reaction mixture was filtered and washed thoroughly with distilled water. The retentates were dried in a vacuum oven at $40^{\circ} \mathrm{C}$ overnight.

\subsection{Microwave apparatus}

MW irradiation was performed in a single mode focused CEM reactor (Model Discover, CEM Co., Matthew, NC) operating at $2.45 \mathrm{GHz}$ with ability to control the output power. The experimental parameters were set up as previously described $[38,40]$. An external cooling circuit maintained constant temperature of the reaction mixture and constant irradiation power. In order to maintain uniform temperature the sample was mixed by magnetic stirring at $400 \mathrm{rpm}$. The PANI MW synthesis using APS was performed at microwave power 0,8 and $93 \mathrm{~W}$. All experiments were done under the same conditions by keeping constant irradiation power, temperature and initial reaction mixture volume. The temperature was maintained at $24 \pm 1^{\circ} \mathrm{C}$ in all experiments.

\subsection{FTIR spectroscopy}

Fourier transform infrared (FTIR) spectra were recorded with resolution $2 \mathrm{~cm}^{-1}$ using a Nicolet 8700 FT-IR spectrometer with $\mathrm{KBr}$ pellets. 100 scans were averaged for each sample.

\subsection{Raman spectroscopy}

Raman spectra were recorded at $1 \mathrm{~cm}^{-1}$ resolution using a Renishaw Raman System-Model 1000 spectrometer with $785 \mathrm{~nm}$ (red) laser excitation.

\subsection{SEM}

SEM was carried out using a Philips XL30S Field Emission Gun with a SiLi (Lithium drifted) EDS detector with Super Ultra Thin Window. The PANI samples were $10 \mathrm{~mm}$ in diameter, mounted on aluminium studs using adhesive graphite tape and sputter coated using a Polaron SC7640 Sputter Coater at 5-10 $\mathrm{mA}$ and $1.1 \mathrm{kV}$ for $5 \mathrm{~min}$.

\subsection{Solid-state NMR spectroscopy}

Solid-state NMR experiments were carried out on dry powder samples using a Bruker AVANCE 300 standard bore magnet system operating at $300.13 \mathrm{MHz}$ proton frequency $(7.05 \mathrm{~T})$. Spectra were obtained by using CP MAS (Cross-Polarization Magic Angle Spinning) technique. The experiments were carried out using a Bruker double resonance broadband probe with zirconium oxide $\left(\mathrm{ZrO}_{2}\right) 7 \mathrm{~mm}$ rotors and Kel-F caps. The magic angle was adjusted by maximizing the sidebands of the ${ }^{79} \mathrm{Br}$ signal of a $\mathrm{KBr}$ sample. The typical parameters for ${ }^{13} \mathrm{C}$ NMR spectroscopy were: a $90^{\circ}$ pulse width of $4.2 \mu \mathrm{s}$, a spinlock field of $62.5 \mathrm{kHz}$, contact time of $1.5 \mathrm{~ms}$, a recycle delay of $1 \mathrm{~s}$ and a spectral-width of $40 \mathrm{kHz}$. Experiments were carried out with 5000 scans at ambient temperature using samples enclosed in the rotors. The ${ }^{13} \mathrm{C}$ chemical shift scale was referenced to tetramethylsilane (TMS). Samples were rotated at $7000 \pm 1 \mathrm{~Hz}$.

\subsection{Electron paramagnetic resonance (EPR) spectroscopy}

EPR spectra of $7.9 \mathrm{mg}$ for the standard sample and $10.5 \mathrm{mg}$ for MW PANI samples in quartz EPR tubes, were recorded at ambient temperature using a JEOL JES-FA 200 EPR spectrometer with modulation amplitude $16 \mathrm{mT}$. The spin concentration was determined using hydrated copper sulphate $\left(\mathrm{CuSO}_{4}\right)$ as a standard. The EPR spectra of the samples and $\mathrm{CuSO}_{4} \cdot 5 \mathrm{H}_{2} \mathrm{O}$ were recorded under the same conditions. The spin concentration, $N_{\text {sample }}$ (spins g ${ }^{-1}$ ) was calculated using the area calculated from the second integral of the first-derivative signals using Matlab according to Equation (1): 
$N_{\text {sample }}=\frac{\text { Area }_{\text {sample }}}{\text { Area }_{\text {reference }}} \cdot \frac{\text { mass }_{\text {reference }}}{\text { mass }_{\text {sample }}} N_{\text {reference }}$

where the reference substance used was $\mathrm{CuSO}_{4} \cdot 5 \mathrm{H}_{2} \mathrm{O}$, for which $N_{\text {reference }}=2.412 \cdot 10^{21}$ spins $\mathrm{g}^{-1}$.

\subsection{X-ray diffraction (XRD) measurements}

To determine the changes in crystallinity and structure of the samples X-ray Diffraction (XRD) measurements were recorded at room temperature on a Panalytical Empyreon powder diffractometer with $\mathrm{Cu} \mathrm{K \alpha}$ radiation $(40 \mathrm{kV}, 40 \mathrm{~mA})$ in transmission mode. Diffraction intensities were measured with a PixCel solid state detector by scanning from 6 to $50^{\circ}$ $(2 \theta)$ with a step size of $0.02^{\circ}(2 \theta)$ at $0.25 \mathrm{sec} / \mathrm{step}$.

\section{Results and discussion}

\subsection{SEM measurements}

SEM micrographs of the samples obtained using the EMS at different power levels using $\mathrm{CH}_{3} \mathrm{COOH}$ and $\mathrm{NH}_{4} \mathrm{OH}$ are shown in Figure 1. The micrographs obtained from the samples synthesized with $\mathrm{CH}_{3} \mathrm{COOH}$ at $8 \mathrm{~W}$ mainly show elongated, tape-like structures. The product obtained after 20 min looks morphologically more homogeneous compared to the 10 min product, showing the presence of nanorods. The morphology of the samples synthesized with $\mathrm{CH}_{3} \mathrm{COOH}$ depends on the microwave power level, as can be seen from the micrographs of the samples synthesized at 8 and $93 \mathrm{~W}(10 \mathrm{~min})$. The product obtained at $93 \mathrm{~W}$ is more morphologically heterogeneous, although it does consist of elongated nanostructures. At the same time the sample

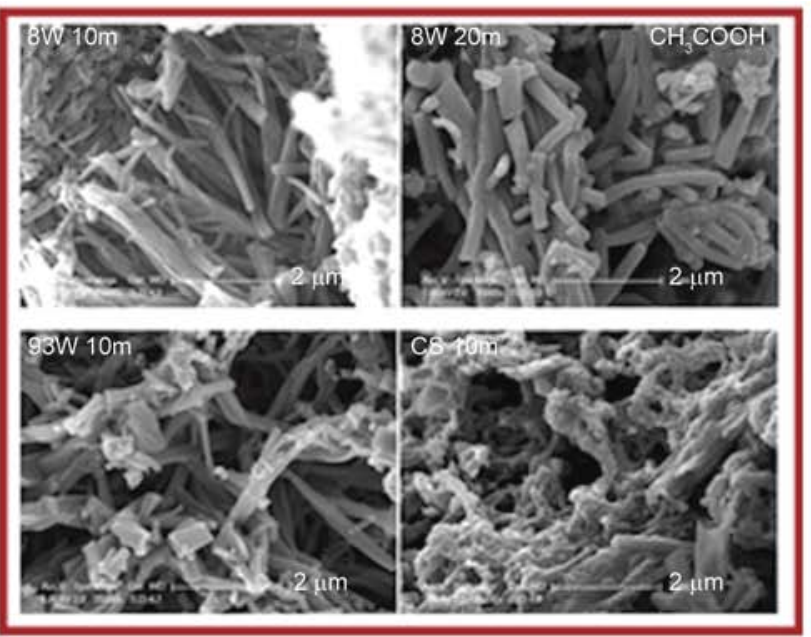

synthesized $0 \mathrm{~W}$ is mainly featureless and microporous.

Samples synthesized with $\mathrm{NH}_{4} \mathrm{OH}$ show different dependence on the microwave power and the reaction time. First, the main products are nanospheres. The samples synthesized at $93 \mathrm{~W}$ are morphologically more uniform compared to the sample obtained at $8 \mathrm{~W}$. Also, it seems that in this case the shorter reaction times favor better defined nanostructures. Overall, the samples synthesized under medium to high $\mathrm{pH}$ conditions exhibit compact and defined nanostructural morphologies. They show differences when obtained on different MW powers and reaction times. The morphologies obtained here are similar to those obtained using a standard approach [15]. However, microwave actuation allows for faster reactions and possibilities for fine tuning of aniline oxidative polymerization $[3,27]$. Due to their distinctive morphological characteristics, samples synthesized after a reaction time of $10 \mathrm{~min}$ for $\mathrm{CH}_{3} \mathrm{COOH}$ and 20 min for $\mathrm{NH}_{4} \mathrm{OH}$ were chosen for structural analysis.

\subsection{FTIR and aman spectroscopy \\ 3.2.1. FTIR spectroscopy}

FTIR spectra of the PANI samples obtained with $\mathrm{CH}_{3} \mathrm{COOH}$ and $\mathrm{NH}_{4} \mathrm{OH}$ are shown in Figure 2. The values in the brackets represent the peak positions in the FTIR spectrum from the sample obtained in the presence of $\mathrm{NH}_{4} \mathrm{OH}$. There is a shoulder at 1641 (1640) $\mathrm{cm}^{-1}$ which can be assigned to a to a hydrogen-bonded $\mathrm{C}=\mathrm{O}$ stretch, i.e., $-\mathrm{C}=\mathrm{O} \cdots \bullet \cdot \mathrm{H}-\mathrm{N}-[5]$. The intense bands and shoulders at $1591(1598) \mathrm{cm}^{-1}$ and the bands at $1504(1511) \mathrm{cm}^{-1}$ are present in all

Figure 1. SEM micrographs of the products obtained with $\mathrm{CH}_{3} \mathrm{COOH}$ (red) and $\mathrm{NH}_{4} \mathrm{OH}$ (blue) at different reaction times

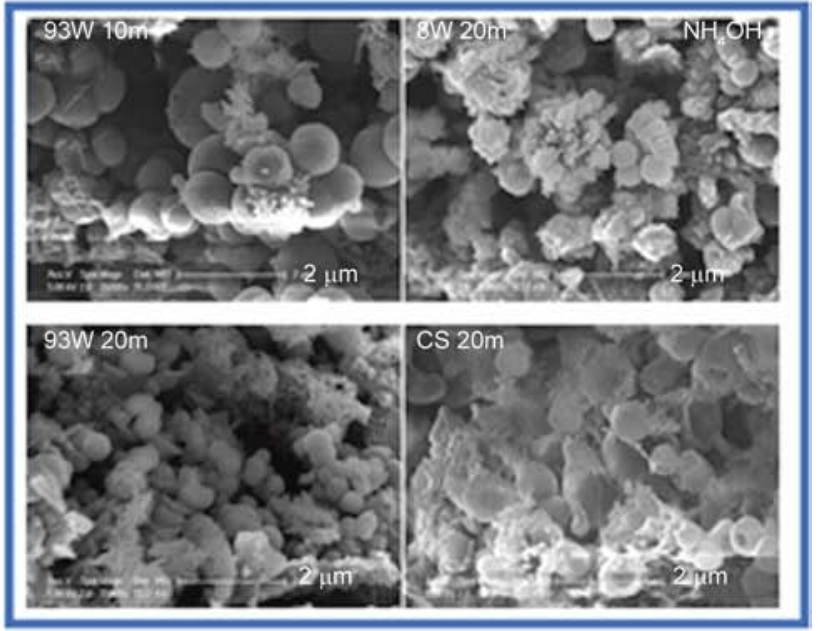



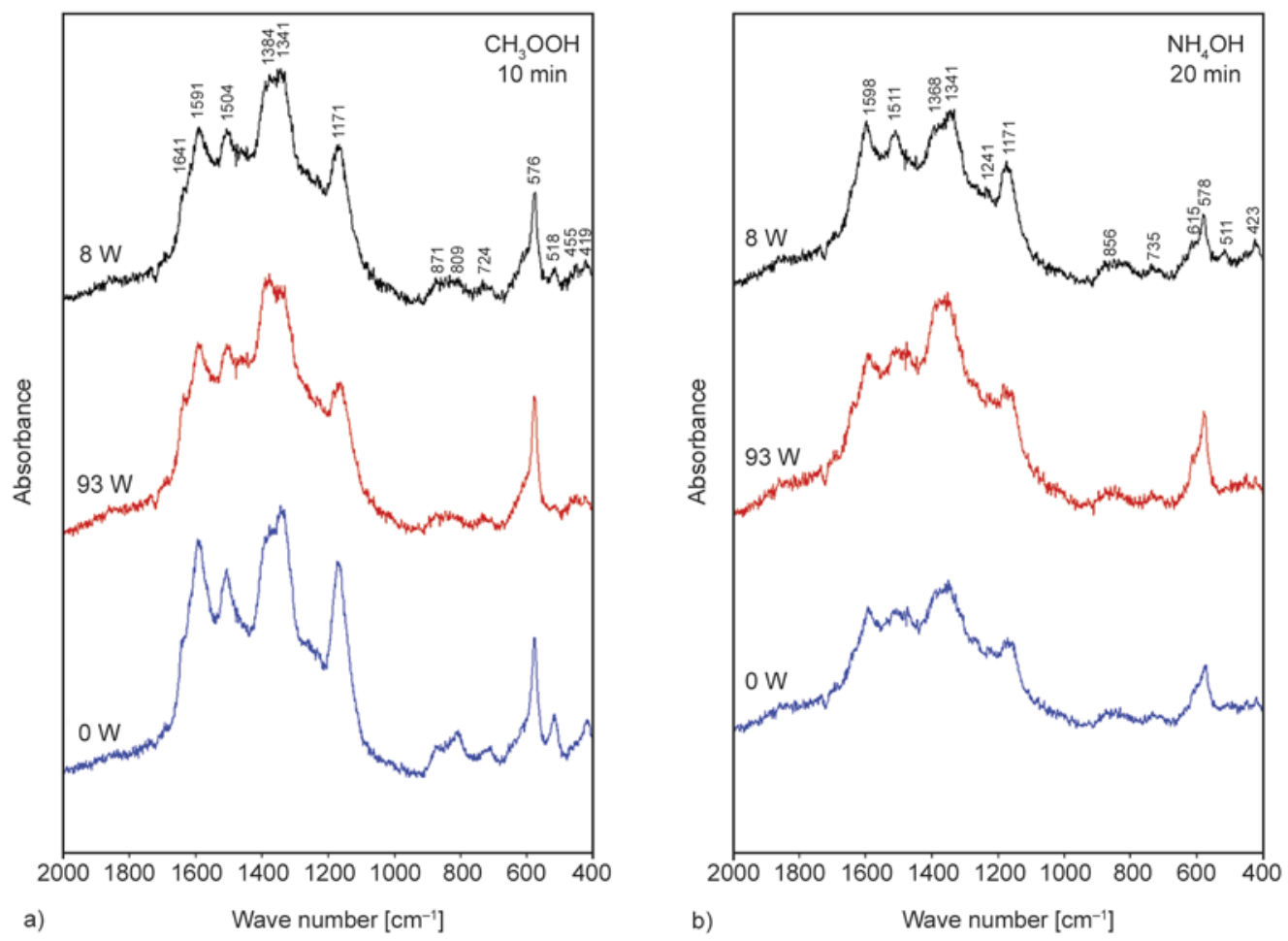

Figure 2. FTIR spectra of the products obtained with $\mathrm{CH}_{3} \mathrm{COOH}(10 \mathrm{~min})$ (a) and $\mathrm{NH}_{4} \mathrm{OH}(20 \mathrm{~min})$ (b) at different microwave powers

spectra (Figure 1) and can be attributed to $\mathrm{C}=\mathrm{C}$ stretching in the quinoid and benzenoid rings, respectively [42]. The band at about $1364(1368) \mathrm{cm}^{-1}$ is attributed to $\mathrm{C}-\mathrm{N}$ stretching [43] or $\mathrm{C}-\mathrm{C}$ stretch in quinoid segments [42]. The peak at $1341(1341) \mathrm{cm}^{-1}$ can be assigned to $\mathrm{C}-\mathrm{N}$ stretching (plus $\mathrm{C}-\mathrm{C}$ stretching) [43] or $\mathrm{C}-\mathrm{H}$ bending in benzenoid units [42]. The band at $1170(1171) \mathrm{cm}^{-1}$ can be due to $\mathrm{C}-\mathrm{H}$ bending in benzenoid structures or it has been often referred as an electronic band [43,44]. This peak is significantly more intense compared to the corresponding peaks from the samples obtained in the EMS syntheses implying the higher degree of delocalization of electrons [44] in these samples. The band at $871(856) \mathrm{cm}^{-1}$ is due to $\mathrm{C}-\mathrm{H}$ out-of-plane bending on three substituted benzene ring [43]. The band at $809 \mathrm{~cm}^{-1}$ can be assigned to out-of-plan C-H bending in the benzenoid units [45]. The band at 724 (735) $\mathrm{cm}^{-1}$ can be assigned to $\mathrm{C}-\mathrm{N}=\mathrm{C}$ bending [42], or $\mathrm{C}-\mathrm{H}$ out-of-plane bending on disubtituted benzene ring [43]. The bands from ca. 500 to $600 \mathrm{~cm}^{-1}$ are due to aromatic ring deformations in the benzenoid and quinoid units $[42,43]$. The band at 419
(423) $\mathrm{cm}^{-1}$ is due ring deformation out-of-plane of the benzenoid ring.

\subsubsection{Raman spectroscopy}

Raman spectra of the samples obtained by MW after 10 and 20 minutes at 93 and $8 \mathrm{~W}$ with $\mathrm{CH}_{3} \mathrm{COOH}$ and $\mathrm{NH}_{4} \mathrm{OH}$ and for the conventional synthesis are shown in Figure 3 (left and right). The bands at 1589 (1589) $\mathrm{cm}^{-1}$ can be assigned to $\mathrm{C}=\mathrm{C}$ stretch in quinoid units [42]. The bands $1511(1489) \mathrm{cm}^{-1}$ are characteristic for $\mathrm{C}=\mathrm{N}$ stretching and $\mathrm{C}-\mathrm{H}$ bending in benzenoid units [42]. The bands $1368(1367) \mathrm{cm}^{-1}$ can be assigned to $\mathrm{C}-\mathrm{C}$ stretching in quinoid units. The band at $1341 \mathrm{~cm}^{-1}$ is assigned to $\mathrm{C}-\mathrm{H}$ bending in benzenoid units [42] while the band at $1231 \mathrm{~cm}^{-1}$ $\left(\mathrm{NH}_{4} \mathrm{OH}\right.$ spectra) belongs to $\mathrm{C}-\mathrm{N}^{+}+\mathrm{C}-\mathrm{C}$ stretching [43]. The bands at $1171(1168) \mathrm{cm}^{-1}, 856(856) \mathrm{cm}^{-1}$ and $735(730) \mathrm{cm}^{-1}$ are attributed to $\mathrm{C}-\mathrm{H}$ bending of the quinoid rings, ring deformations in benzenoid and ring deformations in quinoid units, respectively [42]. The band at $578(578) \mathrm{cm}^{-1}$ is due to a quinoid ring deformation [42]. 

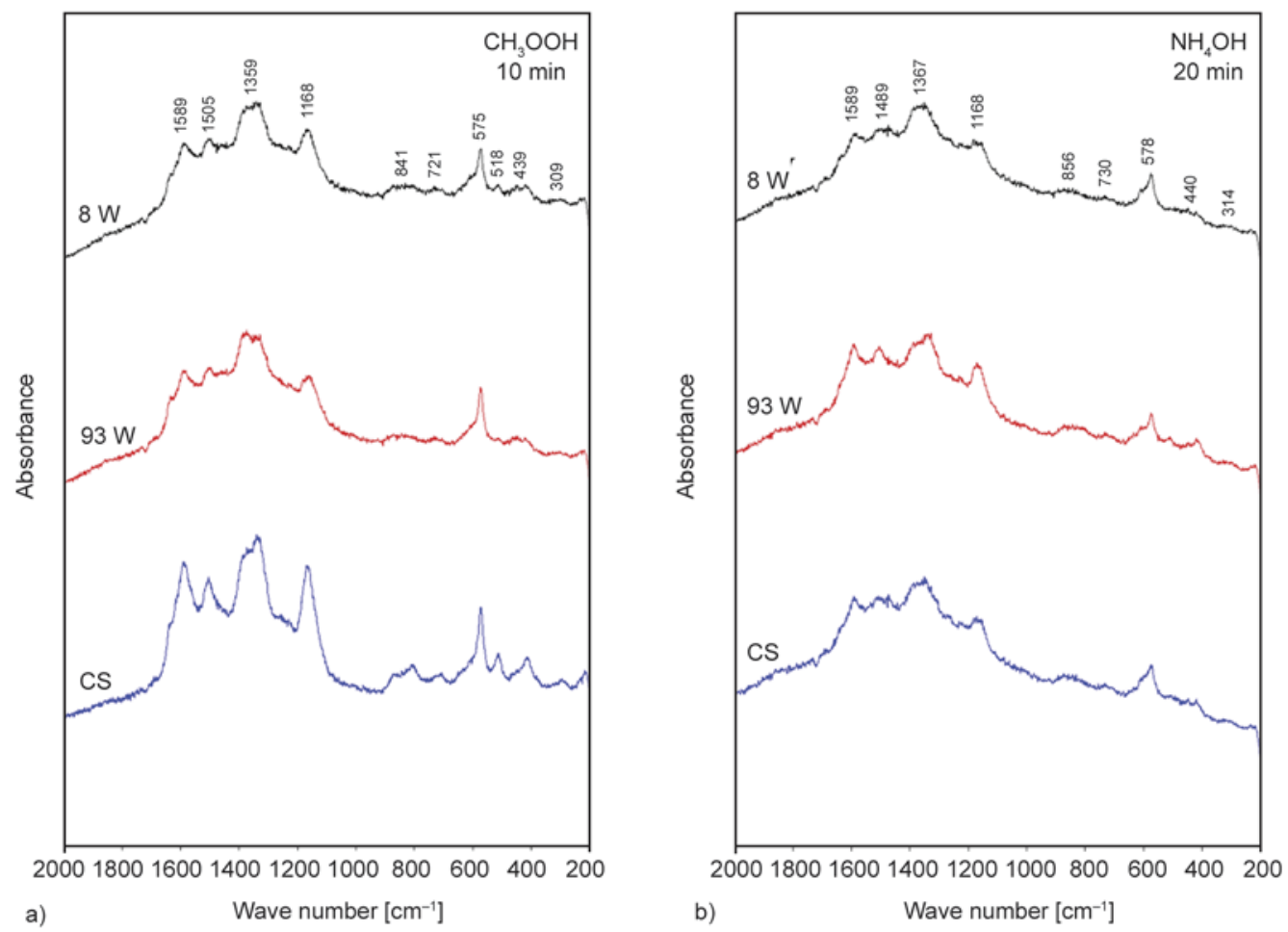

Figure 3. Raman spectra of the products obtained with $\mathrm{CH}_{3} \mathrm{COOH}(10 \mathrm{~min})$ (a) and $\mathrm{NH}_{4} \mathrm{OH}(20 \mathrm{~min})$ (b) at different microwave powers

The FTIR and Raman spectra reveal the presence of quinoid/benzenoid segments in all samples either synthesized conventionally or in the microwave.

\subsection{Solid-state NMR spectroscopy}

The solid-state ${ }^{13} \mathrm{C}$ CPMAS NMR spectra of aniline oxidation products obtained with $\mathrm{CH}_{3} \mathrm{COOH}$ and

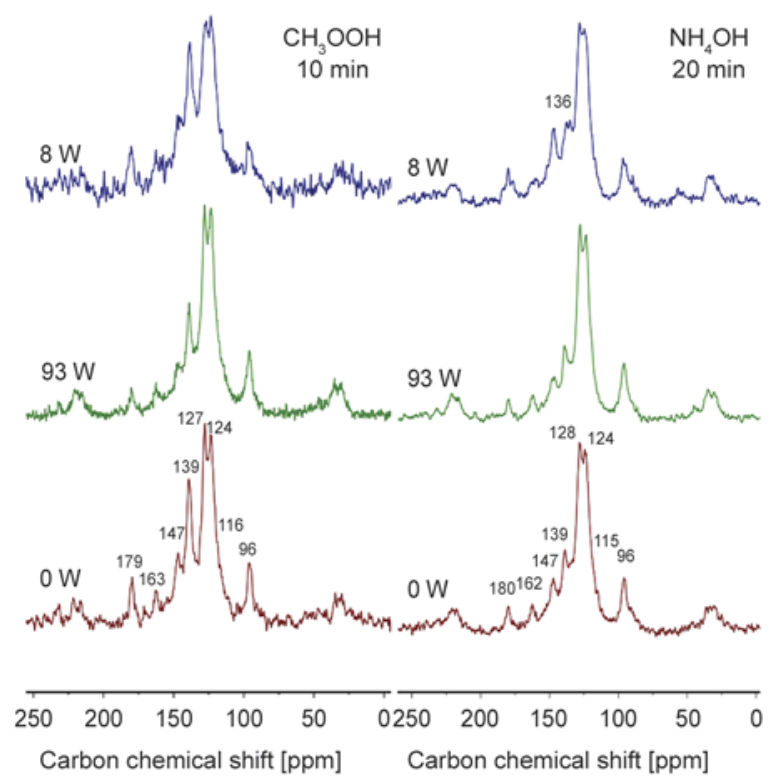

Figure 4. Solid-state NMR spectra of the products obtained with $\mathrm{CH}_{3} \mathrm{COOH}(10 \mathrm{~min})$ and $\mathrm{NH}_{4} \mathrm{OH}(20 \mathrm{~min})$ at different microwave powers
$\mathrm{NH}_{4} \mathrm{OH}$ after 10 and 20 min reaction time at different MW power levels are shown in Figure 4.

The assignment of peaks in the ${ }^{13} \mathrm{C}$ CPMAS spectra shown in Figure 4 is based on data obtained from chemically synthesized PANI [46, 47] (Figure 5 $\alpha$ ) and from the products synthesized using the ' $\mathrm{pH}$ falling' approach (Figure 5 $\beta$ ) $[20,40]$. The peak at ca. $180 \mathrm{ppm}$ (see Figure 4) is usually not seen in the NMR spectra of chemically synthesized PANI.

The $181.5 \mathrm{ppm}$ signal could be due to the presence of carbonyl groups on the six-membered rings (C-9,
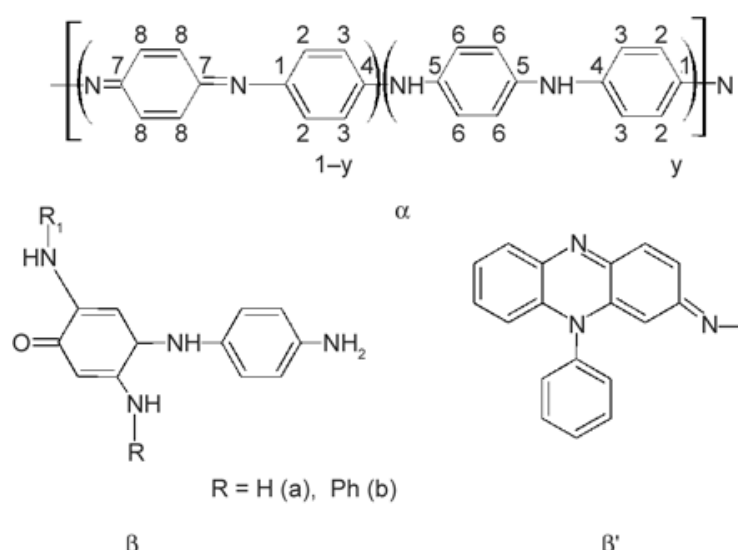<smiles>[R]N=c1ccc2nc3ccccc3n(-c3ccccc3)c-2c1</smiles>

$\beta^{\prime}$

Figure 5. Proposed structural units present in the nanostructured aniline oxidation products obtained at different power levels 
Figure $5 \beta$ ), as proposed previously in studies of the products obtained in the oxidative polymerization of aniline $[5,40]$. The peaks at ca. $163 \mathrm{ppm}$ are assigned to non-protonated imine quinoid carbon (C-7, see Figure 5 $\alpha$ ) [48]. The peaks at ca. $147 \mathrm{ppm}$ are assigned to nonprotonated carbon attached to the imine nitrogen C-1 [40]. This confirms the presence of quinoid rings. The peak at $\approx 140 \mathrm{ppm}$ due to nonprotonated carbons (C-4 and C-5) [40] could be partly overlapped with the peak for protonated quinoid carbon $(\approx 139$ ppm for 'standard' chemically synthesized PANI [46]). The peaks at ca. $124 \mathrm{ppm}$ are assigned to protonated benzenoid carbon $(\mathrm{C}-2,3)$. The resonance at $128 \mathrm{ppm}$ could be attributed to protonated quinoid carbons C-8 [49]. This peak was also partly attributed to the presence of bipolarons i.e. positively charged domains [50]. The peak at $96 \mathrm{ppm}$ found in all spectra (Figure 4) is usually not characteristic for chemically synthesized PANI and it can be due to the presence of branching in the polymer structure (C-10, Figure 5 $\beta$ ) [20]. The spectral features i.e. the differences in the relative peak intensities in the NMR spectra imply the presence of a mixture of aniline oligomeric structures with the presence of quinoid and benzenoid, i.e. PANI segments. These polymerize at a late stage of synthesis.

\subsection{EPR spectroscopy}

The EPR spectra of the products obtained at different microwave power levels in the presence of $\mathrm{CH}_{3} \mathrm{COOH}$ and $\mathrm{NH}_{4} \mathrm{OH}$ are shown in Figures 6 and 7 respectively. The spin concentrations calculated from the second integrals using Equation (1) are

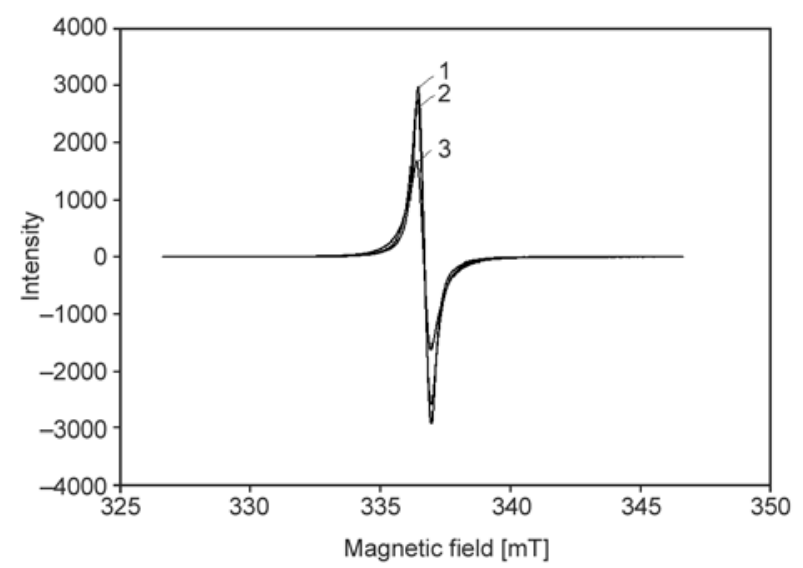

Figure 6. EPR spectra of the samples prepared with $\mathrm{CH}_{3} \mathrm{COOH}$ and taken after $\left.10 \mathrm{~min} 1\right) 0 \mathrm{~W}$; 2) $93 \mathrm{~W}$ and 3) $8 \mathrm{~W}$

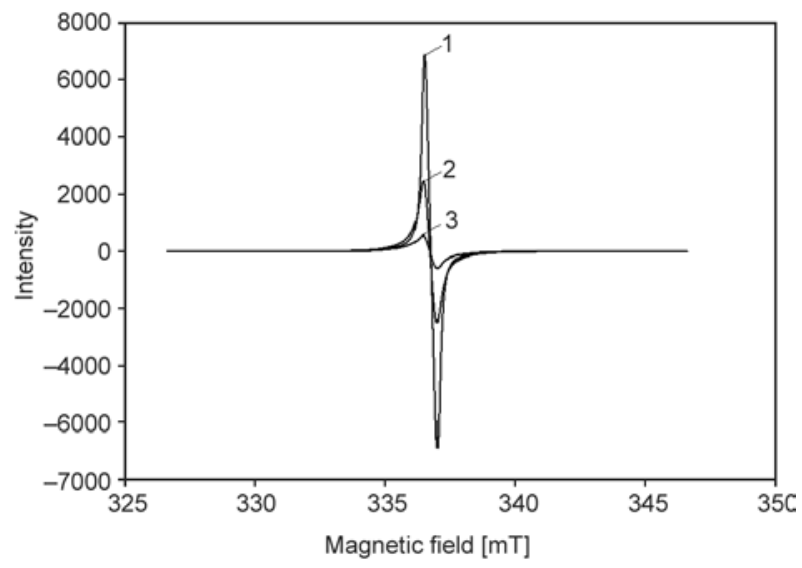

Figure 7. EPR spectra of the samples prepared with $\mathrm{NH}_{4} \mathrm{OH}$ and taken after $20 \mathrm{~min}: 1) 8 \mathrm{~W}$; 2) $93 \mathrm{~W}$ and 3) $0 \mathrm{~W}$

Table 1. Spin concentration $N_{\text {sample }}$ for the synthesized PANIs

\begin{tabular}{|c|c|}
\hline Sample & $\begin{array}{c}\text { Spin concentration } \\
\mathbf{N}_{\text {sample }}\left(\text { spin }^{-\mathbf{- 1}}\right) \cdot \mathbf{1 0}^{19}\end{array}$ \\
\hline $\mathrm{CH}_{3} \mathrm{COOH}$ & 2.333 \\
\hline $\mathrm{CH}_{3} \mathrm{COOH} 93 \mathrm{~W} 10 \mathrm{~min}$ & 2.216 \\
\hline $\mathrm{CH}_{3} \mathrm{COOH} \quad 0 \mathrm{~W} 10 \mathrm{~min}$ & 1.840 \\
\hline $8 \mathrm{~W} 20 \mathrm{~min}$ & 2.278 \\
\hline $93 \mathrm{~W} 20 \mathrm{~min}$ & 2.105 \\
\hline $0 \mathrm{~W} 20 \mathrm{~min}$ & 0.758 \\
\hline
\end{tabular}

given in Table 1. For both reaction media the use of microwave radiation results in an increase in the spin concentration, which is slightly greater for $8 \mathrm{~W}$ than for $93 \mathrm{~W}$ irradiation power level. Microwave irradiation also causes a slight increase in the EPR linewidth; in the case of the reaction in $\mathrm{CH}_{3} \mathrm{COOH}$, this results in the EPR signals for the MW synthesized products obtained at 8 and $93 \mathrm{~W}$ having lower peak intensities than that for the $0 \mathrm{~W}$ product (Figure 6), despite the fact that the latter has the lowest spin concentration (Table 1). In the case of reaction in $\mathrm{NH}_{4} \mathrm{OH}$, the spin concentration for the $0 \mathrm{~W}$ product is much lower, so that the order of the EPR peak intensities (Figure 7) is the same as that of the spin concentrations (Table 1), although here again the line-broadening effect of MW irradiation in the synthesis is evident in the considerably lower peak intensity of the signal for the $93 \mathrm{~W}$ relative to the $8 \mathrm{~W}$ sample (Figure 7). EPR signals in PANI are due to the formation of polarons upon protonation and doping of the PANI by acid [51] and this is presumably the cause of the signals observed in the present study, the dopant acid being $\mathrm{H}_{2} \mathrm{SO}_{4}$ produced by reduction of APS in the oxidation of aniline. 


\subsection{XRD measurements}

To investigate structural characteristics of the samples obtained powder XRD measurements were carried out. XRD patterns of the samples obtained with $\mathrm{CH}_{3} \mathrm{COOH}$ exhibit sharp lines in the region of $5^{\circ}<2 \theta<50^{\circ}$ (Figure 8a). This implies long-range ordering in this sample. The main diffraction peaks are at $2 \theta$ values of $6.5,16.2,17.9,19.1,23.3,23.6$, $26.2,26.5,27.0,30.3$ and less intensive peaks at $32.8,33.4,36.6,36.2,38.5,40.4$, and 40.7. The peaks at $2 \theta=6.5$ implies very long range order, which can be assigned to the periodicity caused by the aniline/dopant acid salt [52]. The peaks at 17.9 and $26.2^{\circ}$ can be attributed to the periodicity parallel and perpendicular to the polymer chains, respectively [52-54]. The peaks at ca. 23 and also at $26^{\circ}$ could be due to a periodicity caused by $\pi-\pi$ stacking of rigid phenazine-like structures [53]. At the same time the
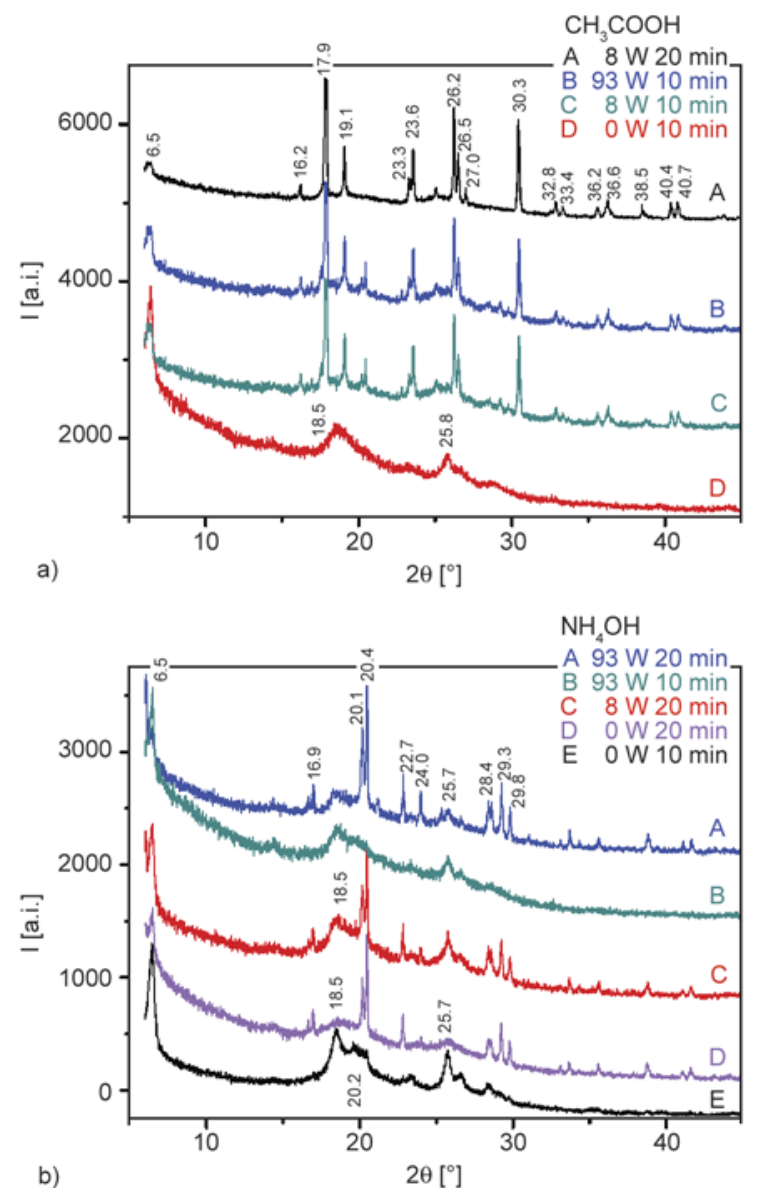

Figure 8. XRD patterns of the samples prepared with $\mathrm{CH}_{3} \mathrm{COOH}$ (a) and $\mathrm{NH}_{4} \mathrm{OH}$ (b) collected at different power levels and reaction times sample obtained at $0 \mathrm{~W}$ shows broad reflection due to the presence of amorphous phases. This is very interesting as it implies that samples obtained in the presence of MWs have significantly more ordered structure.

XRD patterns of the samples obtained with $\mathrm{NH}_{4} \mathrm{OH}$ in the presence of MWs also show sharp lines (Figure $8 \mathrm{~b}$ ), except for the $10 \mathrm{~min}$ sample obtained at $93 \mathrm{~W}$. The position of sharp peaks is close to those shown in Figure 8a and the same assignment can apply. XRD patterns of the samples obtained at $0 \mathrm{~W}$ show mixed crystallinity. That is, 10 min sample shows broad peaks, while the 20 min sample exhibit very sharp peaks. This could imply that in the first 10 min regardless of microwave power an amorphous phase is formed, and then with time progressing more crystalline structures are obtained. These findings can be very interesting as MW can be used for the formation of very well ordered structures.

\section{Conclusions}

MW assisted aniline oxidative polymerization syntheses under medium and high $\mathrm{pH}$ are performed for the first time. SEM micrographs showed that products obtained after 10 and 20 min consist of either nanorods (in the presence of $\mathrm{CH}_{3} \mathrm{COOH}$ ) or nanospheres (in the presence of $\mathrm{NH}_{4} \mathrm{OH}$ ). Based on solidstate NMR, FTIR and Raman data it was shown that branched structures with the existence of the benzenoid/quinoid segments prevail in the final products. This is not surprising considering that the syntheses started at medium and high $\mathrm{pH}$. An increase in the spin concentration is slightly more evident for $8 \mathrm{~W}$ than for $93 \mathrm{~W}$ power level, according to EPR spectroscopy. XRD data suggest the presence of well-ordered (crystal-like) structures.

Here, it is worth highlighting the fact that the MW approach can be used for the formation of self-assembled nanorods and nanospheres. This is interesting as it is well known that self-assembly favors longer reaction times for complex, supramolecular structures to be formed. Self-assembly of aniline based products (polyanilines or oligoanilines) is quite complicated subject especially in the presence of microwaves. Additional work is needed to understand the complex formation mechanisms in the microwaveassisted polymerization. 


\section{Acknowledgements}

The authors acknowledge financial support Ministry of Science and Environmental Protection of Serbia (Contract No. 172015) and PBRF Fund School of Chemical Sciences, the University of Auckland. The authors would like to thank Dr Michel Nieuwoudt for her asistence with FTIR, Raman and EPR spectroscopies.

\section{References}

[1] Wallace G. G., Spinks G. M., Kane-Maguire L. A. P.: Conductive electroactive polymers: Intelligent materials systems. CRC Press, Boca Raton (2002).

[2] Skotheim T. A., Reynolds J. R.: Handbook of conducting polymers, conjugated polymers processing and applications. CRC Press, Boca Raton (2007).

[3] Gizdavic-Nikolaidis M. R., Stanisavljev D. R., Easteal A. J., Zujovic Z. D.: A rapid and facile synthesis of nanofibrillar polyaniline using microwave radiation. Macromolecular Rapid Communications, 31, 657-661 (2010). DOI: $10.1002 /$ marc. 200900800

[4] Huang J., Kaner R. B.: A general chemical route to polyaniline nanofibers. Journal of the American Chemical Society, 126, 851-855 (2004).

DOI: $10.1021 / \mathrm{ja} 0371754$

[5] Venancio E. C., Wang P-C., MacDiarmid A. G.: The azanes: A class of material incorporating nano/micro self-assembled hollow spheres obtained by aqueous oxidative polymerization of aniline. Synthetic Metals, 156, 357-369 (2006).

DOI: 10.1016/j.synthmet.2005.08.035

[6] Wei Z., Zhang Z., Wan M.: Formation mechanism of self-assembled polyaniline micro/nanotubes. Langmuir, 18, 917-921 (2002).

DOI: $10.1021 / 1 a 0155799$

[7] Zhang L., Wan M.: Self-assembly of polyaniline From nanotubes to hollow microspheres. Advanced Functional Materials, 13, 815-820 (2003). DOI: $10.1002 / \mathrm{adfm} .200304458$

[8] Zhang Z., Wan M., Wei Y.: Highly crystalline polyaniline nanostructures doped with dicarboxylic acids. Advanced Functional Materials, 16, 1100-1104 (2006). DOI: $10.1002 / \mathrm{adfm} .200500636$

[9] Ćirić-Marjanović G.: Polyaniline nanostructures. in 'Nanostructured conductive polymers' (ed.: Eftekhari A.) Wiley, London, 19-98 (2010).

[10] Ćirić-Marjanović G., Dondur V., Milojević M., Mojović M., Mentus S., Radulović A., Vuković Z., Stejskal J.: Synthesis and characterization of conducting selfassembled polyaniline nanotubes/zeolite nanocomposite. Langmuir, 25, 3122-3131 (2009).

DOI: $10.1021 / 1 a 8030396$

[11] Ćirić-Marjanović G., Trchová M., Stejskal J.: The chemical oxidative polymerization of aniline in water: Raman spectroscopy. Journal of Raman Spectroscopy, 39, 1375-1387 (2008).

DOI: $10.1002 /$ jrs.2007
[12] Konyushenko E. N., Stejskal J., Šeděnková I., Trchová M., Sapurina I., Cieslar M., Prokeš J.: Polyaniline nanotubes: Conditions of formation. Polymer International, 55, 31-39 (2006). DOI: $10.1002 /$ pi.1899

[13] Stejskal J., Sapurina I., Trchová M., Konyushenko E. N., Holler P.: The genesis of polyaniline nanotubes. Polymer, 47, 8253-8262 (2006). DOI: $10.1016 /$ j.polymer.2006.10.007

[14] Stejskal J., Spirkova M., Riede A., Helmstedt M., Mokreva P., Prokes J.: Polyaniline dispersions 8. The control of particle morphology. Polymer, 40, 24872492 (1999).

DOI: $10.1016 / \mathrm{S} 0032-3861(98) 00478-9$

[15] Konyushenko E. N., Trchová M., Stejskal J., Sapurina I.: The role of acidity profile in the nanotubular growth of polyaniline. Chemical Papers, 64, 56-64 (2010). DOI: $10.2478 / \mathrm{s} 11696-009-0101-\mathrm{z}$

[16] Ćirić-Marjanović G., Konyushenko E. N., Trchová M., Stejskal J.: Chemical oxidative polymerization of anilinium sulfate versus aniline: Theory and experiment. Synthetic Metals, 158, 200-211 (2008).

DOI: $10.1016 /$ j.synthmet.2008.01.005

[17] Tran H. D., D’Arcy J. M., Wang Y., Beltramo P. J., Strong V. A., Kaner R. B.: The oxidation of aniline to produce 'polyaniline': a process yielding many different nanoscale structures. Journal of Materials Chemistry, 21, 3534-3550 (2011).

DOI: $10.1039 / \mathrm{c} 0 \mathrm{jm} 02699 \mathrm{a}$

[18] Laslau C., Zujovic Z., Travas-Sejdic J.: Theories of polyaniline nanostructure self-assembly: Towards an expanded, comprehensive multi-layer theory (MLT). Progress in Polymer Science, 35, 1403-1419 (2010). DOI: $10.1016 /$ j.progpolymsci.2010.08.002

[19] Laslau C., Zujovic Z. D., Zhang L., Bowmaker G. A., Travas-Sejdic J.: Morphological evolution of selfassembled polyaniline nanostuctures obtained by $\mathrm{pH}-$ stat chemical oxidation. Chemistry of Materials, 21, 954-962 (2009).

DOI: $10.1021 / \mathrm{cm} 803447 \mathrm{a}$

[20] Zujovic Z. D., Laslau C., Bowmaker G. A., Kilmartin P. A., Webber A. L., Brown S. P., Travas-Sejdic J.: Role of aniline oligomeric nanosheets in the formation of polyaniline nanotubes. Macromolecules, 43, 662-670 (2010).

DOI: $10.1021 / \mathrm{ma902109r}$

[21] Zujovic Z. D., Laslau C., Travas-Sejdic J.: Lamellarstructured nanoflakes comprised of stacked oligoaniline nanosheets. Chemistry - An Asian Journal, 6, 791796 (2011).

DOI: $10.1002 /$ asia.201000703

[22] Gerbec J. A., Magana D., Washington A., Strouse G. F.: Microwave-enhanced reaction rates for nanoparticle synthesis. Journal of the American Chemical Society, 127, 15791-15800 (2005). DOI: $10.1021 / j a 052463 \mathrm{~g}$ 
[23] Seijas J. A., Vázquez-Tato M. P., Martínez M. M., Rodríguez-Parga J.: Microwave enhanced synthesis of acridines. A new aspect in the Bernthsen reaction. Green Chemistry, 4, 390-391 (2002).

DOI: $10.1039 / \mathrm{B} 204243 \mathrm{~F}$

[24] Ayele D. W., Chen H-M., Su W-N., Pan C-J., Chen LY., Chou H-L., Cheng J-H., Hwang B-J., Lee J-F.: Controlled synthesis of CdSe quantum dots by a microwave-enhanced process: A green approach for mass production. Chemistry - A European Journal, 17, 5737-5744 (2011).

DOI: 10.1002/chem.201003686

[25] Wu C-C., Shiau C-Y., Ayele D. W., Su W-N., Cheng MY., Chiu C-Y., Hwang B-J.: Rapid microwave-enhanced solvothermal process for synthesis of $\mathrm{CuInSe}_{2}$ particles and its morphologic manipulation. Chemistry of Materials, 22, 4185-4190 (2010).

DOI: $10.1021 / \mathrm{cm} 1006263$

[26] Lange J. H. M., Verveer P. C., Osnabrug S. J. M., Visser G. M.: Rapid microwave-enhanced synthesis of 4hydroxyquinolinones under solvent-free conditions. Tetrahedron Letters, 42, 1367-1369 (2001). DOI: $10.1016 / \mathrm{s} 0040-4039(00) 02244-9$

[27] Gizdavic-Nikolaidis M. R., Stanisavljev D. R., Easteal A. J., Zujovic Z. D.: Microwave-assisted synthesis of functionalized polyaniline nanostructures with advanced antioxidant properties. The Journal of Physical Chemistry C, 114, 18790-18796 (2010). DOI: $10.1021 / j p 106213 \mathrm{~m}$

[28] Kappe C. O., Dallinger D., Murphree S. S.: Practical microwave synthesis for organic chemists: Strategies, instruments, and protocols. Wiley-VHC, Weinheim (2009).

[29] Kappe C. O., Stadler A.: Microwaves in organic and medicinal chemistry. Wiley-VHC, Weinheim (2005).

[30] Antonio C., Deam R. T.: Can 'microwave effects' be explained by enhanced diffusion? Physical Chemistry Chemical Physics, 9, 2976-2982 (2007).

DOI: 10.1039/B617358F

[31] de la Hoz A., Dyaz-Ortiz A., Moreno A.: Microwaves in organic synthesis. Thermal and non-thermal microwave effects. Chemical Society Reviews, 34, 164-178 (2005).

DOI: $10.1039 / \mathrm{B} 411438 \mathrm{H}$

[32] Perreux L., Loupy A.: A tentative rationalization of microwave effects in organic synthesis according to the reaction medium, and mechanistic considerations. Tetrahedron, 57, 9199-9223 (2001).

DOI: $10.1016 / \mathrm{S} 0040-4020(01) 00905-\mathrm{X}$

[33] Kappe C. O., Pieber B., Dallinger D.: Microwave effects in organic synthesis: Myth or reality? Angewandte Chemie International Edition, 52, 1088-1094 (2013). DOI: 10.1002/anie.201204103

[34] Dudley G. B., Stiegman A. E., Rosana M. R.: Correspondence on microwave effects in organic synthesis. Angewandte Chemie International Edition, 52, 79187923 (2013).

DOI: $10.1002 /$ anie.201301539
[35] Gizdavic-Nikolaidis M. R., Jevremovic M., Stanisavljev D. R., Zujovic Z. D.: Enhanced microwave synthesis: Fine-tuning of polyaniline polymerization. The Journal of Physical Chemistry C, 116, 3235-3241 (2012).

DOI: $10.1021 / j p 2086939$

[36] Adams P. N., Laughlin P. J., Monkman A. P., Kenwright A. M.: Low temperature synthesis of high molecular weight polyaniline. Polymer, 37, 3411-3417 (1996). DOI: $10.1016 / 0032-3861(96) 88489-8$

[37] Stejskal J., Riede A., Hlavatá D., Prokeš J., Helmstedt M., Holler P.: The effect of polymerization temperature on molecular weight, crystallinity, and electrical conductivity of polyaniline. Synthetic Metals, 96, 5561 (1998). DOI: 10.1016/s0379-6779(98)00064-2

[38] Zhang L., Peng H., Zujovic Z. D., Kilmartin P. A., Travas-Sejdic J.: Characterization of polyaniline nanotubes formed in the presence of amino acids. Macromolecular Chemistry and Physics, 208, 1210-1217 (2007). DOI: $10.1002 / \mathrm{macp} .200700013$

[39] Zhang L., Zujovic Z. D., Peng H., Bowmaker G. A., Kilmartin P. A., Travas-Sejdic J.: Structural characteristics of polyaniline nanotubes synthesized from different buffer solutions. Macromolecules, 41, 88778884 (2008). DOI: $10.1021 / \mathrm{ma} 801728 \mathrm{j}$

[40] Zujovic Z. D., Zhang L., Bowmaker G. A., Kilmartin P. A., Travas-Sejdic J.: Self-assembled, nanostructured aniline oxidation products: A structural investigation. Macromolecules, 41, 3125-3135 (2008).

DOI: $10.1021 / \mathrm{ma} 071650 \mathrm{r}$

[41] Laslau C., Zujovic Z. D., Travas-Sejdic J.: Polyaniline 'nanotube' self-assembly: The stage of granular agglomeration on nanorod templates. Macromolecular Rapid Communications, 30, 1663-1668 (2009).

DOI: $10.1002 /$ marc.200900244

[42] Boyer M-I., Quillard S., Rebourt E., Louarn G., Buisson J. P., Monkman A., Lefrant S.: Vibrational analysis of polyaniline: A model compound approach. The Journal of Physical Chemistry B, 102, 7382-7392 (1998). DOI: $10.1021 / \mathrm{jp} 9726520$

[43] Tang J., Jing X., Wang B., Wang F.: Infrared spectra of soluble polyaniline. Synthetic Metals, 24, 231-238 (1988). DOI: 10.1016/0379-6779(88)90261-5

[44] MacDiarmid A. G., Epstein A. J.: The concept of secondary doping as applied to polyaniline. Synthetic Metals, 65, 103-116 (1994). DOI: 10.1016/0379-6779(94)90171-6

[45] Harada I., Furukawa Y., Ueda F.: Vibrational spectra and structure of polyaniline and related compounds. Synthetic Metals, 29, 303-312 (1989). DOI: 10.1016/0379-6779(89)90311-1 
[46] Kaplan S., Conwell E. M., Richter A. F., MacDiarmid A. G.: Solid-state carbon-13 NMR characterization of polyanilines. Journal of American Chemical Society, 110, 7647-7651 (1988).

DOI: $10.1021 / \mathrm{ja} 00231 \mathrm{a} 011$

[47] Kaplan S., Conwell E. M., Richter A. F., MacDiarmid A. G.: A solid-state NMR investigation of the structure and dynamics of polyanilines. Synthetic Metals, 29, 235-242 (1989).

DOI: $10.1016 / 0379-6779(89) 90301-9$

[48] Zujovic Z. D., Nieuwoudt M., Bowmaker G. A., Kilmartin P. A.: Nanostructures obtained in the oxidative polymerization of aniline: Effects of polarons. Polymer, 54, 6363-6372 (2013).

DOI: 10.1016/j.polymer.2013.09.020

[49] Thiyagarajan M., Kumar J., Samuelson L. A., Cholli A. L.: Enzymatically synthesized conducting polyaniline nanocomposites: A solid-state NMR study. Journal of Macromolecular Science Part A: Pure and Applied Chemistry, 40, 1347-1355 (2003).

DOI: $10.1081 / \mathrm{MA}-120025314$

[50] Kababya S., Appel M., Haba Y., Titelman G. I., Schmidt A.: Polyaniline-dodecylbenzene sulfonic acid polymerized from aqueous medium: A solid state NMR characterization. Macromolecules, 32, 5357-5364 (1999). DOI: $\underline{10.1021 / \mathrm{ma} 982010 \mathrm{e}}$
[51] Kang Y., Lee H., Namgoong J., Jung B., Lee H.: Decrease in electrical conductivity upon oxygen exposure in polyanilines doped with $\mathrm{HCl}$. Polymer, 40, 2209-2213 (1999). DOI: $10.1016 / \mathrm{S} 0032-3861(98) 00441-8$

[52] Wang Z., Liao F., Yang S., Guo T.: A novel route synthesis of poly(ortho-phenylenediamine) fluffy microspheres self-assembled from nanospheres. Fibers and Polymers, 12, 997-1001 (2011) DOI: $10.1007 / \mathrm{s} 12221-011-0997-0$

[53] Jiang H., Sun X., Huang M., Wang Y., Li D., Dong S.: Rapid self-assembly of oligo(o-phenylenediamine) into one-dimensional structures through a facile reprecipitation route. Langmuir, 22, 3358-3361 (2006). DOI: $10.1021 / \mathrm{la} 053091 \mathrm{~s}$

[54] Jin E., Liu N., Lu X., Zhang W.: Novel micro/nanostructures of polyaniline in the presence of different amino acids via a self-assembly process. Chemistry Letters, 36, 1288-1289 (2007). DOI: $\underline{10.1246 / \mathrm{cl} .2007 .1288}$ 